\title{
Estratégia de Fusão e AQuisição Bancária no BRASIL: EVIDÊNCIAS EMPÍRICAS SOBRE RETORNOS
}

Carlos Alberto Gonçalves de Araújo

Professor Universitário do CET-FAESA/ES

Mestrando em Ciências Contábeis pela FUCAPE/ES ca.araujo@gmail.com

Fábio Goldner

Professor Universitário da UNIVIL A/ES Mestrando em Ciências Contábeis pela FUCAPE/ES frgoldner@uol.com.br

Marcelo Moll Brandão

Professor Universitário da FABAVI/ES Mestrando em Ciências Contábeis pela FUCAPE/ES mollmkt@gmail.com

Fernando Rodrigues Oliveira Professor Universitário da Faculdade Cândido Mendes/ES Mestrando em Ciências Contábeis pela FUCAPE/ES fernando.vix@gmail.com 


\section{RESUMO}

A partir do Plano Real as instituições financeiras atuantes no mercado brasileiro passaram por um grande processo de ajustes. Com isto houve uma redução significante dos números de players e diversos bancos foram liquidados ou transferiram o seu controle acionário através dos processos de fusões e aquisições. Esta mudança provocada no cenário competitivo teve como aliados o desenvolvimento tecnológico e ambiente regulatório. O presente artigo analisa o impacto das fusões e aquisições nos retornos realizadas no âmbito dos bancos brasileiros privados adquirentes de controle nacional e estrangeiro. Especificamente, este trabalho investigou o impacto que estes processos causaram no Retorno sobre o Patrimônio Líquido (ROE) e no Retorno sobre os Ativos (ROA) dos bancos adquirentes. A metodologia aplicada neste trabalho foi uma pesquisa empírico-analítica e a base de dados utilizada foi o ranking dos 50 maiores bancos por ativo do Brasil, publicada pelo BACEN, no período compreendido entre 2000 e 2004. A amostra considerada neste trabalho inclui apenas os bancos que possuíam dados em todos os anos pesquisados. Os resultados evidenciam que os processos de fusão e aquisição não impactaram nos retornos dos bancos adquirentes, tanto em relação aos ativos quanto ao patrimônio líquido (ROA e ROE, respectivamente). A Teoria Neoclássica da Maximização dos Lucros da Firma, que explica que os processos de fusão e aquisição são motivados pela maximização dos retornos dos bancos adquirentes, não foi confirmada neste estudo.

Palavras-chave: Fusão, Aquisição, Retornos dos Bancos, Desenvolvimento Tecnológico, Ambiente Regulatório.

\section{ABSTRACT}

In the years subsequent to the implementation and consolidation of Plano Real, the financial institutions operating in the Brazilian market underwent a substantial process of adjustments. As a result, there was a significant reduction in the number of players and several banks either liquidated or transferred their stock control through processes of mergers and acquisitions (M\&A). This change, which was caused by a competitive scenario, had both technological development and regulatory environment as its allies. This paper analyzes the impact of the $M \odot A$ in the returns undertaken in the sphere of the private Brazilian banks that have acquired national and foreign control. Specifically, this work investigates the impact these processes caused on the Return on Equity (ROE) and in the Return on the Assets (ROA) of the acquiring banks. The methodology applied to this work involved an empirical and analytical research and the database used ranked the 50 largest banks by assets in Brazil as published by BACEN in the period between 2000 and 2004. The sample considered in this work only includes the banks that possessed data in all of the researched years. The results evidence that $M \& A$ processes had no impact on the acquiring banks 'returns with regard to both assets and equity (ROA and $\mathrm{ROE}$, respectively). The Neoclassical Theory of the Maximization of the Profits of the Firm, which establishes that M\&A processes are motivated by the maximization of the acquiring banks' returns, was not confirmed in this study

Key words: Mergers, Acquisitions, Bank Returns, Technological Development, Regulatory Environment. 


\section{INTRODUÇÃO E CONTEXTUALIZAÇÃO}

Nos últimos anos o ambiente do sistema financeiro nacional vem sofrendo grandes transformações oriundas, principalmente, da evolução tecnológica, da internacionalização dos negócios e da busca de alternativas estratégicas para a conquista de novos mercados.

Com a abertura dos mercados nacionais os países incluem nos seus instrumentos estratégicos a desregulamentação e flexibilização do setor financeiro, uma vez que o aumento da concorrência e a redução dos preços dos serviços prestados estão pautados nestas mudanças.

Uma das estratégias freqüentemente utilizadas pelos bancos no sistema brasileiro foram os processos de fusões e aquisições (F\&A). Nessas circunstâncias, o sistema financeiro brasileiro percebeu que poderia ganhar escala e participação nos mercados utilizando-se destes mecanismos. A magnitude dos valores envolvidos e a quantidade de transações de F\&A realizadas no Brasil no período após a implantação do Plano Real já representariam, por si só, uma justificativa plausível.

Uma metodologia alternativa às diversas utilizadas nos estudos empíricos nacionais e internacionais é proposta neste trabalho. A base de dados aqui utilizada será composta pelos 50 maiores bancos por ativos no Brasil, publicada anualmente pelo BACEN.

Para Rappaport (1998), o objetivo básico das F\&As é gerar e adicionar valor para as empresas e para os acionistas. Entretanto, é muito difícil determinar se realmente houve criação de valor, principalmente para os acionistas. Para Firth (1980), a Teoria Neoclássica da Maximização dos Lucros da Firma explica as motivações do processo de F\&A. Esta teoria postula que as forças do mercado competitivo motivam as firmas a maximizar o retorno das empresas adquirentes. Segundo o autor, as firmas se engajarão no processo de F\&A se estes resultarem no aumento da riqueza dos acionistas adquirentes, advindo de aumento na rentabilidade.

Dessa forma, esta pesquisa busca responder à seguinte pergunta: Os bancos adquirentes que participaram das F\&As no setor bancário brasileiro aumentaram seus retornos? Assim, o objetivo geral deste trabalho é analisar o impacto das F\&As nos retornos dos bancos brasileiros privados adquirentes, no período compreendido entre 2000 e 2004. Especificamente, procura-se verificar o impacto causado no Retorno sobre o Patrimônio Líquido (ROE) e no Retorno sobre os Ativos (ROA) dos bancos adquirentes em decorrência destes processos de transferência do controle acionário.

No Brasil da década de 90 houve um crescimento significativo nos processos de F\&As dos bancos. Segundo Kupfer e Hasenclever (2002), de 1990 a 1999, o setor financeiro representou $12,4 \%$ do valor e 18,3\% do número das Transações de F\&A no Brasil. Em segundo lugar, conforme os autores, está o Setor Alimentar com 3,6\% e 7,7\%, respectivamente.

O pressuposto teórico deste trabalho é que os processos de F\&A aumentam os retornos das empresas adquirentes; assim, tem como hipótese que estes processos acontecidos no período de 1995 a 2004 aumentaram o ROA e o ROE dos bancos adquirentes.
Para testar tal hipótese foi utilizado um modelo de regressão com dados em painel, nos termos da proposta de Basu et al (2004). Esse tipo de análise já foi testado em outros países, mas é distinta dos vários estudos sobre o tema já realizados no Brasil.

A pertinência do tema pode ser medida uma vez que o processo de consolidação da indústria bancária brasileira já caminhou enormemente; há, entretanto, etapas a serem percorridas. Assim, o presente trabalho contribui para a escassa literatura sobre F\&A em mercados emergentes e para o atual debate acerca da concentração no setor bancário e dos seus efeitos sobre os retornos dos bancos adquirentes, mediante teste empírico das teorias já desenvolvidas e promoção de um patamar para novas pesquisas.

A próxima seção revê, brevemente, aspectos teóricos e estudos empíricos anteriores, os quais relacionaram os processos de F\&As aos retornos. As considerações metodológicas com ênfase nas operacionalizações do modelo são discutidas em seqüência. Os resultados e a sua discussão aparecem na seção seguinte; o trabalho se encerra com as conclusões, os possíveis caminhos a serem trilhados e as sugestões de outros estudos.

\section{REFERENCIAL TEÓRICO}

\subsection{Conceito de fusão e aquisição}

Existem procedimentos legais que podem ser utilizados pelas empresas para adquirir outra empresa: a) fusão ou consolidação; b) aquisição de ações; e c) aquisição de ativos (ROSS; WESTERFIELD; JAFFE, 2002).

Fusão significa, segundo a literatura internacional, que uma empresa absorveu outra. Normalmente, a empresa que procede à absorção conserva seu nome e sua identidade. Todos os ativos e passivos são absorvidos por esta. Uma consolidação é muito parecida com a fusão, exceto pelo fato de que, neste processo, há a criação de uma nova empresa (ROSS; WESTERFIELD; JAFFE, 2002).

Já para Gitman (2002), as fusões são formas de expansão que as empresa utilizam e que devem ser empreendidas somente quando se espera que o valor da ação da empresa adquirente seja elevado. Não obstante, outras razões imediatas - como diversificação e vantagens tributárias - são motivadores desses processos. Todos eles, segundo o autor, poderão resultar em ganho para a empresa adquirente.

Uma outra forma de se adquirir uma empresa é por meio da compra de ações com direito a voto. Tal operação normalmente acontece em mercados de capitais, através de pagamento em dinheiro, ações ou com outros títulos. A aquisição ocorre quando uma empresa ou grupo de investidores adquire, de forma total ou parcial, o controle acionário de uma outra empresa (TRICHES, 1996).

Para Ross, Westerfield e Jaffe (2002), esse tipo de compra pode se dar através de uma oferta privada, de uma administração interessada, à outra. Logo em seguida, esta oferta é comunicada aos acionistas, por uma oferta geral de compra. Uma oferta geral de compra é "uma oferta pública de compra de ações de uma empresa visada”. 
Nesta modalidade uma empresa pode adquirir a outra através da compra de todos os seus ativos. Neste caso, segundo Ross, Westerfield e Jaffe (2002), é exigida dos acionistas da empresa vendedora uma aprovação formal.

\subsection{Classificação das fusões e aquisições}

Segundo Ross, Westerfield e Jaffe (2002), uma F\&A pode ser:

- Horizontal - Caracterizada pela união entre firmas que são atuantes no mesmo segmento de atividade; normalmente, são concorrentes.

- Vertical - Caracterizada pela união de duas firmas que fazem parte do mesmo processo produtivo. Esse tipo de F\&A pode ser para cima, em direção aos fornecedores, ou para baixo, em direção aos distribuidores (CAMARGOS e BARBOSA, 2003).

- Conglomerado - Caracterizada quando a firma adquirente e adquirida não pertencem ao mesmo ramo de atividade; o principal objetivo da organização compradora é a diversificação do investimento.

\subsection{Teoria das fusões e aquisições}

Para Kloeckner (1994), até o exato momento não há uma teoria geral sobre o processo de F\&A de empresas. O que existe, segundo o autor, é um conjunto de explicações que se propõem conferir legitimidade ao assunto, vinculada a aspectos específicos de algumas teorias da empresa, principalmente da Teoria da Firma e da Teoria da Agência.

A evolução da atividade de F\&A é passada por movimentos cíclicos chamado de ondas. Estes movimentos possuem grandes destaques nos estudos internacionais, principalmente na academia norte-americana. O quadro 1 descreve estes processos e detalha suas principais características.

A onda de F\&A dos anos 80 caracterizou-se pela extrema facilidade de recursos internos e externos para investimento. Além desta facilidade, a experiência negativa com a formação de conglomerados econômicos altamente diversificados na década de 60 ajudou no processo (TRICHES, 1996).

Para Camargos e Barbosa (2003), nos anos 80 houve uma expansão empresarial não em novas plantas, mas em processos de F\&A. Em parte, segundo os autores, devido ao baixo valor das ações no mercado de capitais.

Para Triches (1996), a década de 90 é vista como a adequação inteligente a ambiente de negócios em constante mutação. As causas são as mais diversas, como mercado em retração, reformas governamentais e mudanças na tecnologia.

De forma geral, o mercado mundial de F\&A tende à maior concentração dos mercados, através de empresas que estão à procura de atuação em áreas nas quais possuam maior capacitação tecnológica ou em que tenham pleno domínio dos métodos produtivos. Uma outra tendência no contexto internacional é o investimento fora do seu mercado doméstico.

É consenso na literatura internacional que o processo de F\&A constitui um fenômeno de destaque no cenário econômico internacional, já que é uma forma rápida, e muitas vezes eficiente, de crescimento de uma firma. Segundo Triches (1996), existem evidências empíricas que demonstram que as várias formas de associação se intensificam quando as economias estão com altas taxas de crescimento e possuem recursos financeiros disponíveis.

\begin{tabular}{|l|l|}
\hline Primeira Onda de F\&A & $\begin{array}{l}\text { Caracterizada pelas grandes transformações nos transportes, nas comunicações, nas } \\
\text { tecnologias de manufatura, consolidações nas indústrias de petróleo, aço, tabaco e outras } \\
\text { áreas básicas, além da formação de grandes monopó lios. }\end{array}$ \\
\hline $\begin{array}{l}\text { Segunda Onda de F\&A } \\
(1916-1929)\end{array}$ & $\begin{array}{l}\text { Pelo motivo do boom do mercado de capitais, os investidores financeiros buscaram } \\
\text { consolidar as firmas em vários setores, como o de serviços de utilidade pública (elétrico e de } \\
\text { gás), comunicações e o automobilístico. Esta onda apresentou mais fusões por integração } \\
\text { vertical e diversificação do que a precedente e foi caracterizada por fusões que visavam ao } \\
\text { poder de oligopólio. }\end{array}$ \\
\hline Terceira Onda de F\&A & $\begin{array}{l}\text { Predominaram as fusões que visavam à diversificação, do tipo conglomerado, com a união } \\
\text { de diferentes atividades, como uma resposta às maiores restrições às fusões horizontais e } \\
\text { verticais introduzidas pelas alterações nas leis antitrustes em 1950. Durante os anos } 60, \text { as } \\
\text { aquisições foram influenciadas pelo boom do mercado de capitais e encorajadas por } \\
\text { inovações nos mecanismos financeiros. }\end{array}$ \\
\hline $\begin{array}{l}\text { Quarta Onda de F\&A } \\
\text { (Década de 80) }\end{array}$ & $\begin{array}{l}\text { Caracterizada pela expansão através da aquisição de outras firmas, e não em novas plantas. } \\
\text { O principal motivo desta onda foi o baixo valor das ações no mercado de capitais. O boom } \\
\text { das F\&As dos anos } 80 \text { na economia norte -americana visava principalmente à expansão } \\
\text { internacional das grandes corporações multinacionais. }\end{array}$ \\
\hline
\end{tabular}

Quadro 1. As ondas de Fusões e Aquisições no mundo.

Fonte: Adaptado de Camargos e Barbosa (2003) 


\subsection{Motivação para os processos de Fusão e Aquisição}

No entendimento de Kloeckner (1994), entre os vários motivos de F\&A está a busca por economia. Para ele, muitas economias de escala, como custos fixos mais baixos em função do aumento do nível de produção, poderiam ser obtidas com este processo.

Além deste, a economia de escopo pode ser considerada como uma segunda motivação dos processos de F\&A. Como exemplo, uma empresa poderia transferir a outra um know how de tecnologia aplicável a uma variedade de produtos sem que, necessariamente, este conhecimento fosse feito através do mercado (KLOECKNER, 1994, p.49). Esta transferência de know bow dentro da firma evita, conclui o mesmo autor, a necessidade de negociações sucessivas e diminui o risco de oportunismos, tornando-a mais eficaz.

Para Brigham, Gapenski e Ehrhardt (2001), a lógica por trás das F\&As é a sinergia; esta segundo é a principal motivação da maior parte dos processos. Através da sinergia é possível aumentar o retorno da empresa adquirente. Além da sinergia, Brigham, Gapenski e Ehrhardt (2001) citam: a) o efeito da tributação; b) a compra de ativos abaixo do seu custo de reposição; e c) a diversificação.

O efeito da tributação como motivação dos processos de F\&A acontece quando a empresa adquirente, por ser mais lucrativa, possui uma alta taxa de imposto de renda e, assim, poderá minimizar o pagamento destes impostos através do acúmulo dos prejuízos das empresas adquiridas. Estes impostos poderiam se transformar em economias imediatas para as adquirentes. Kloeckner (1994) pontua: as evidências empíricas dos estudos internacionais que utilizaram esta hipótese não forneceram o suporte necessário para considerar que esta hipótese fosse aceita. Para o autor, compensar as obrigações da empresa adquirente junto à Receita Federal com o acúmulo dos prejuízos daquela empresa não foi evidenciado como fator motivador dos processos de F\&A.

A compra de ativos abaixo do seu custo de reposição como fator motivador dos processos de F\&A acontece quando uma empresa opta por adquirir uma outra empresa, por entender que o custo de reposição dos seus ativos é maior que seu valor de mercado. Como exemplo, Brigham, Gapenski e Ehrhardt (2001) falam que, nos EUA na década de 80, as empresas petrolíferas podiam adquirir reservas mais baratas através da compra de outras companhias de petróleo do que fazendo, elas mesmas, a exploração dos poços.

Por último, a diversificação do portifólio por meio dos processos de F\&A é caracterizada pelo argumento de que diversificar os investimentos da empresa seria uma forma de ajudar a estabilizar os seus lucros e que, assim, poderia beneficiar seus proprietários (BRIGHAM, GAPENSKI E EHRHARDT, 2001).

\subsubsection{A F\&A e a Teoria Neoclássica de Maximização dos Lucros da Firma}

Para Firth (1980), as forças competitivas do mercado motivarão as empresas a maximizar os ganhos dos acionistas. Tal teoria prediz que as firmas se engajarão nos processos de F\&A, caso resultem no aumento dos retornos da empresa adquirentes. Este aumento poderá advir da criação de poder de mercado, através da sinergia ou através de injeção superior de gerenciamento nas firmas adquiridas.

\subsubsection{Incentivos Pessoais dos Gestores}

Além da Teoria da Maximização dos Lucros da Firma, os incentivos pessoais dos gestores é um outro ponto muito discutido na academia internacional. Quando as decisões de investimentos nos processos de F\&A são motivadas somente por considerações econômicas, especialmente aquelas que irão maximizar os benefícios dos gestores, esta decisão é conhecida como Teoria da Maximização da Utilidade Gerencial.

Na visão de Kloeckner (1994), um motivador recorrente na literatura internacional ocorre quando acontece F\&A que implique no aumento do bem-estar dos diretores das empresas compradoras, mesmo que a operação de F\&A cause impacto negativo no valor de mercado de suas ações.

Para Firth (1980), a Teoria da Maximização da Utilidade Gerencial pressupõe que, além de conseguir um nível satisfatório dos lucros, os gerentes tentarão maximizar seus próprios interesses. Ao contrário da Teoria da Maximização dos Lucros da Firma, esta teoria não prediz que o aumento da riqueza dos gerentes requeira a maximização dos retornos da firma.

Kloeckner (1994) afirma que existem duas teorias explicando as razões gerenciais que motivam as F\&As: a Teoria do Mercado de Controle Corporativo e a Teoria de Fluxo de Caixa Livre.

A Teoria do Mercado Corporativo foi proposta por Manne (1965). Em seu artigo o autor tem como premissa que o controle corporativo não depende de qualquer ganho econômico. Além disso, existe correlação positiva entre desempenho gerencial e o preço da ação da empresa. Isto quer dizer que o mercado reage negativamente ao preço das ações das empresas em que os diretores não procuram maximizar os retornos da empresa adquirente.

E ainda: quando uma empresa com uma equipe de diretores e gerentes mais competente adquire uma empresa mal administrada, é provável que o preço de mercado das ações aumente, proporcionando um ganho de capital aos investidores (KLOECKNER, 1994).

Não existem controles internos perfeitos, tão pouco dispositivos extras que forcem uma diretoria a maximizar os lucros - é o que afirmam Shleifer e Vishny (1988). Assim, a F\&A seria uma forma de remover uma diretoria ineficiente e que não buscasse maximizar o retorno das empresas adquirentes (KLOECKNER, 1994).

Já a Teoria do Fluxo de Caixa Livre foi proposta por Jensen (1986) e tem como premissa que os diretores usarão a disponibilidade de caixa da empresa a fim de buscar o crescimento da mesma. Nem sempre estes projetos possuem um valor presente líquido positivo.

O quadro 2 descreve um resumo dos principais motivos das F\&A, seus condicionantes e seus aspectos intrínsecos.

\subsection{Os antecedentes empíricos sobre f\&a}

Sicherman e Pettway (1987) estudaram o impacto dos ganhos dos acionistas através da aquisição de ativos diversificados. Para os autores, a teoria financeira não suporta a diversificação dos negócios; as evidências empíricas de diversificação dos 


\begin{tabular}{|c|c|}
\hline Expectativas Assimétricas & $\begin{array}{l}\text { Diferentes expectativas sobre o futuro levam os investidores a atribuírem valores diferentes } \\
\text { a uma mesma firma, ocasionando propostas de compra. }\end{array}$ \\
\hline $\begin{array}{l}\text { Irracionalidade Individual } \\
\text { nas Decisões de Dirigentes }\end{array}$ & $\begin{array}{l}\text { Justificativa hipotética para as F\&As, segundo a qual, sob condições de incerteza, os indivídu - } \\
\text { os nem sempre tomam decisões racionais. Irracionalidades estas, diluídas ou anuladas quando } \\
\text { consideradas de forma agregada na interação dos vários agentes econômicos (ROLL, 1986). }\end{array}$ \\
\hline $\begin{array}{l}\text { Compensações e Incentivos } \\
\text { Tributários }\end{array}$ & $\begin{array}{l}\text { Advindos de créditos tributários, relativos a prejuízos acumulados por uma das firmas } \\
\text { envolvidas poderem ser compensados em exercícios futuros pela outra firma que venha } \\
\text { apresentando lucros. }\end{array}$ \\
\hline $\begin{array}{l}\text { Custos de Reposição e } \\
\text { Valores de Mercado }\end{array}$ & $\begin{array}{l}\text { Situação existente quando os custos de reposição dos ativos de uma firma forem maiores } \\
\text { que o seu valor de mercado. Isto é, quando a razão "Q de Tobin" (valor de mercado/valor } \\
\text { patrimonial) de uma da firma for menor do que a unidade ("Q de Tobin" < } 1 \text { ). }\end{array}$ \\
\hline & $\begin{array}{l}\text { Advindas de possíveis reduções nos custos em função do aumento do nível de produção, } \\
\text { maior racionalização do esforço de pesquisa e desenvolvimento, uso conjunto de insumos } \\
\text { específicos não divisíveis e transferência d e tecnologia e conhecimento (know-how). }\end{array}$ \\
\hline $\begin{array}{l}\text { Efeitos Anticompetitivos e } \\
\text { Busca do Poder de } \\
\text { Monopólio }\end{array}$ & $\begin{array}{l}\text { Advindos de ganhos com o aumento da concentração de mercado e da conseqüente } \\
\text { redução da competição }\end{array}$ \\
\hline $\begin{array}{l}\text { Redução do Risco de } \\
\text { Insolvência }\end{array}$ & $\begin{array}{l}\text { Advindo da fusão entre duas ou mais firmas com fluxos de caixa sem correlação perfeita } \\
\text { (F\&As conglomerado e co-seguro) }\end{array}$ \\
\hline Razões Gerenciais & $\begin{array}{l}\text { As F\&As podem ocorrer visando tanto o aumento do bem -estar dos diretores das firmas, } \\
\text { mesmo que a operação cause impacto negativo no valor de merc ado de suas ações, como a } \\
\text { substituição de diretores que não estejam maximizando o valor de mercado de suas firmas. }\end{array}$ \\
\hline $\begin{array}{l}\text { Capacidades Adicionais e } \\
\text { Sinergias Operacionais }\end{array}$ & $\begin{array}{l}\text { Devido ao crescimento da demanda e à expectativa de aumento na riqueza dos acionistas } \\
\text { como resultado da fusão }\end{array}$ \\
\hline
\end{tabular}

Quadro 2. Quadro Resumo dos Motivos das F\&A.

Fonte: Camargos e Barbosa (2004).

negócios através das F\&A não foram eficientes em demonstrar que houve ganhos para os acionistas adquirentes. Foram utilizados dados de 147 operações de F\&A no mercado norte-americano no período de 1983 a 1985. A metodologia utilizada foi o estudo de eventos. O anúncio do processo de F\&A foi colhido no Wall Street Journal e a população analisada era listada ou na NYSE ou na AMEX Exchanges.

Sicherman e Pettway (1987) encontraram dois resultados importantes. Primeiro, há no estudo uma influência da linha de produto sobre a diversificação dos ativos e os ganhos das firmas; segundo, existe uma condição financeira da empresa vendedora (adquirida) acima dos retornos anormais dos acionistas da empresa adquirente.

Nesta pesquisa, o tipo de produto foi determinante nos processos de diversificação dos ativos e os lucros decorrentes dos processos de F\&A foram transferidos para os acionistas das empresas adquiridas.

Assim, conclui Sicherman e Pettway (1987), geram-se evidências de que o processo de F\&A estudado foi motivado pelas preferências gerenciais em detrimento dos ganhos dos acionistas.

Gosh (2001) apresenta, em seu estudo, uma pesquisa com 315 amostras de empresas adquirentes e adquiridas no mercado norte-americano. Com a premissa de que a F\&A melhora a performance operacional, o autor analisou os dados contábeis obtidos do Compustat Industrial and Research no ano de 1998 e no CRSP NYSE, AMEX e na NASDAQ e Wall Street Journal.

O estudo não encontrou nenhuma evidência de aumento na performance financeira (operating cash flow performance) nas empresas que participaram do processo de F\&A. Uma con- tribuição importante encontrado no trabalho do referido autor foi a forma de análise. Enquanto vários estudos focaram os retornos obtidos nas ações das empresas, Gosh (2001) analisou a performance financeira através de dados contábeis.

Utilizando dados de sete anos, Dodd (1980) analisou, com base num estudo de evento, uma amostra de 151 anúncios públicos de propostas de F\&A no mercado norte-americano. Desta amostra, 71 anúncios foram completados e 80 foram canceladas após o anúncio público inicial. As empresas eram listadas no NYSE (New York Stock Exchange) e os anúncios foram coletados nos principais meios de notícias financeiras (Wall Street Journal, Moody's Industrial Manual e o Standard and Poor's Corporation Records).

Os principais resultados encontrados no trabalho de Dodd (1980) foram que os acionistas de empresas adquiridas obtiveram grandes retornos anormais positivos após o anúncio da proposta de F\&A.

Shleifer e Vishny (1988) analisaram o processo de F\&A sob a ótica das perspectivas gerenciais. Partindo do pressuposto que as F\&A são direcionadas pelo comportamento não-maximizador de parte dos gerentes das empresas adquirentes, eles discutiram o fato de que uma grande parcela dos processos de F\&A no mercado norte-americano poderia ser explicada pela Teoria da Maximização da Utilidade Gerencial. Na visão dos autores, há limitações nos vários mecanismos designados para manter os interesses dos gestores e dos acionistas caminhando de mãos dadas.

Esta interpretação sugere que, através do processo de F\&A, os gerentes possuem uma forma eficaz de entrar em uma nova linha de negócio e assim poder maximizar seus ganhos (como 
manter o emprego, aumentar o salário, dispor de maiores privilégios). As decisões de F\&A baseada em objetivos gerenciais não sinalizam uma ótima alocação dos recursos dos acionistas adquirentes (SHLEIFER; VISHNY, 1988).

Shleifer e Vishny (1988) concluem a pesquisa sugerindo algumas mudanças nos mecanismos criados para manter os interesses dos acionistas e dos gestores. A principal delas é que o board de diretores deveria ser compensado com ações da empresa (stock options). Assim, os diretores seriam incentivados a maximizar os retornos da empresa, uma vez que o reflexo desta maximização beneficiaria a si próprio.

\subsection{Os estudos sobre F\&A no setor bancário}

Há consenso de que o processo de F\&A tem por objetivo alavancar vantagens competitivas para a empresa, através da geração de poder de mercado. Seguindo a tendência mundial da década de 80 , houve um processo importante de F\&A nos sistema financeiro brasileiro. Segundo Nakane e Alencar (2004), entre 1994 e 2003, o número de instituições financeiras bancárias no Brasil sofreu uma redução de $33 \%$, envolvendo liquidação, aquisição e privatização de bancos estatais.

Para Nakane e Alencar (2004), o setor bancário brasileiro passou por grandes transformações nos últimos 10 anos. Após a implantação e consolidação do Plano Real, muitas transformações levaram o sistema financeiro brasileiro a uma onda de F\&A, que no mundo, principalmente no mercado norte-americano e no mercado europeu, já era uma realidade. Estas transformações, segundo os autores, estão relacionadas com o desenvolvimento tecnológico e com as alterações no ambiente regulatório que aumentaram a concorrência no setor.

Entretanto, a consolidação do setor financeiro trouxe consigo a questão do papel das agências reguladoras. Para responder a esta questão, é necessário estar atento à situação da economia e do setor financeiro (NAKANE; ALENCAR, 2004).

Nakane e Alencar (2004) chamam a atenção para o entendimento de que os processos de fusões e aquisições no setor bancário, como em qualquer outro setor, exigem a investigação de suas conseqüências para o cenário de concorrência. Para os autores, é necessário desenvolver uma metodologia que analise os atos de concentração no setor bancário brasileiro, principalmente nas peculiaridades que nossa economia reserva.

Patrocínio, Kayo e Kimura (2005), em recentes pesquisas internacionais sugerem que uma das principais motivações para os processos de F\&A está na tentativa das empresas adquirentes de incorporarem ativos intangíveis de propriedade da empresa alvo. Estes ativos proporcionam importantes fontes de vantagens competitivas sustentáveis e oportunidades de crescimento. Tais oportunidades podem criar barreiras de entrada aos novos players.

Para que uma estratégia de F\&A crie valor é preciso identificar uma competência distinta como oportunidade no ambiente. Esta oportunidade pode ser a quantidade de recursos obtidos pela empresa adquirente em relação à quantidade total presente na economia, ou a disponibilidade de oportunidades para utilizar tais recursos (PATROCÍNIO; KAYO; KIMURA, 2005).

Como a década de 80 a 90 foi caracterizada pela onda de F\&A no sistema financeiro, uma pergunta é muito pertinente:
Por que os bancos fazem fusão ou aquisição? Para responder a esta questão, Focareli, Panetta e Salleo (2003) estudaram o mercado italiano no período de 1985 a 1996.

Para eles, como para Nakane e Alencar (2004), as inovações tecnológicas e a desregulamentação do setor bancário impulsionaram a onda de F\&A do setor no mundo iniciada nos Estados Unidos e na Europa.

Apesar de a hipótese de redução de custos e do crescimento de oportunidades ser enfatizada em vários estudos e teorias, a literatura internacional tem falhado em encontrar resultados empíricos convincentes destas vantagens nos processos de F\&A (FOCARELI; PANETTA; SALLEO, 2003).

Partindo desta motivação, Focareli, Panetta e Salleo (2003) analisaram os motivos eficientes para as F\&A sob duas óticas. A primeira foi a segregação da análise dos processos de fusão e dos processos de aquisição, isto porque os processos podem ter motivações diferentes e conduzir a resultados diferentes. A segunda foi uma análise das motivações de F\&A ex ante com as conseqüências em sua performance expost.

Os resultados encontrados por Focareli, Panetta e Salleo (2003) estão em consonância com a hipótese de que as F\&A dos bancos italianos são direcionadas por estratégias que almejam a venda de novos produtos e serviços. Além disso, os processos de fusão provavelmente acontecem nos casos em que um dos bancos é menos orientado ao serviço. Assim, a fusão os motivaria a aumentar sua receita com serviços.

Já as aquisições, de acordo com os autores, são orientadas para bancos com uma administração de crédito pobre. Estes bancos almejam reestruturar o portifólio de empréstimos dos bancos adquiridos, melhorando esta política de forma que resulte em maiores lucros.

Utilizando o modelo de estudos de eventos, Brito, Batistella e Famá (2005) analisaram os retornos anormais nas ações de três instituições financeiras (Bradesco, Itaú e Unibanco) que participaram ativamente do processo de F\&A no período de 1997 a 2003. Os resultados corroboram as evidências encontradas por outros autores internacionais, revelando que os retornos anormais positivos não foram significativamente superiores aos retornos anormais negativos. Desta forma, concluem os autores, não houve aumento na riqueza dos acionistas das empresas adquirentes.

A explicação para estes resultados, diferente do que a hipótese de maximização dos lucros preconiza, está no conceito de que o mercado é o melhor avaliador dos benefícios gerados por uma F\&A. Assim, na visão de Brito, Batistella e Famá (2005), os resultados encontrados revelam que os investidores não perceberam que a F\&A geraria benefícios para as empresas adquirentes.

Brito, Batistella e Famá (2005) concluem: apesar de os testes indicarem que os retornos anormais das empresas adquirentes não maximizaram a riqueza dos acionistas, isto não quer dizer que os negócios não geraram benefícios futuros, como poder de mercado e ganhos de escala.

Esta recente onda de F\&A no cenário bancário brasileiro envolveu, inicialmente, a compra de bancos com problemas por bancos saudáveis. Em seguida, estes processos foram tomados por compradores mais fortes e às vezes, alvos fracos, 
mas não insolventes. Entre estes bancos adquiridos, pode-se citar o BCN pelo Bradesco, o Noroeste pelo Santander e o Real pelo ABN-Amro (PAULA, 2004).

Para Paula (2004), no começo dos processos de F\&A, estas operações envolveram bancos Europeus como adquirentes na maioria dos casos. Diferentemente do que aconteceu na Argentina, onde os processos de F\&A estrangeiras incluíram dois dos três maiores bancos privados, no Brasil, estes processos têm envolvido principalmente bancos de tamanho médio. Isto reflete, de forma parcial, o fato de que a capitalização de mercado dos maiores bancos brasileiros torna inviável sua compra.

Apesar do início dos processos de F\&A ter sido comandado pelos bancos europeus, a principal aquisição aconteceu no ano de 2000. O Banco Santander comprou o Banespa por USD 3,7 bilhões, soma cinco vezes maior do que seu valor registrado. Com esta aquisição, o Santander pulou alguns degraus no ranking dos bancos brasileiros por ativo, tornando-se o terceiro maior banco privado do Brasil e o quinto na posição geral dos bancos, incluindo bancos públicos (PAULA, 2004).

A partir deste processo os três maiores bancos privados domésticos, o Bradesco, Itaú e Unibanco, passaram a reagir à penetração dos bancos estrangeiros, participando ativamente dos processos de F\&A, com algumas importantes compras. Para Paula (2004), Itaú e Unibanco passaram a atacar fortemente o Bradesco, principal banco brasileiro privado. O comportamento destes dois bancos foi tomar a forma de uma reação defensiva, já que eles procuraram manter sua posição no mercado, e as F\&A foi uma forma eficiente de evitar a ameaça de serem comprados por outros bancos.

Paula (2004) conclui que a entrada dos bancos europeus no Brasil não trouxe mudanças significativas. Para o autor, não existe evidências claras que os bancos estrangeiros no Brasil têm sido mais eficientes que os bancos privados domésticos, e o que foi criado a partir de 1995 foi uma reorientação estratégica da atividade financeira.

\section{METODOLOGIA}

Este artigo tem como proposta metodológica um estudo empírico analítico, a partir da construção teórica da hipótese. Para análise e teste desta hipótese utilizou-se um modelo econométrico de análise de regressão múltipla de dados.

Ademais, será utilizada a pesquisa documental. Segundo Gil (2002), a pesquisa documental vale-se de materiais que ainda não receberam nenhum tipo de tratamento analítico e que podem ser reelaborados de acordo com os objetivos da pesquisa. Os documentos tratados aqui foram os balanços patrimoniais das empresas da amostra.

\subsection{Seleção da amostra}

Foram coletados os dados dos balanços anuais para mais de 100 bancos brasileiros; cada balanço informava mais de 50 itens diferentes. Os dados incluem informação do setor privado, público e de bancos estrangeiros e cobrem o período 1995 a 2004; foram disponibilizados pelo Banco Central do Brasil, através do seu site institucional.

A seleção das informações foi baseada no conglomerado bancário em cuja composição se verifica pelo menos uma instituição do tipo Banco Comercial ou Banco Múltiplo com Carteira Comercial.

Cada relatório contém mais de 130 instituições bancárias, que compõem os maiores bancos por ativo do Sistema Financeiro Nacional para cada ano pesquisado. Como nem todas as instituições aparecem em todos os anos consecutivamente, o resultado final de todos os bancos analisados ficou em 232 , com informações de 1995 a 2004.

De acordo com a Lei 4.595/64, as instituições financeiras devem apurar resultados a 30 de junho e 31 de dezembro de cada ano, obrigatoriamente, com observância das regras contábeis estabelecidas pelo Conselho Monetário Nacional. Desta forma, os demonstrativos de resultado de junho e dezembro registram os valores acumulados de janeiro a junho e de julho a dezembro, respectivamente.

O quadro 3 demonstra todos os bancos analisados nesta pesquisa.

\begin{tabular}{|l|l|l|l|}
\hline ABC-Brasil & Banpara & Bmb & Credibel \\
\hline Abn Amro & Banrisul & BMC & Crediplan \\
\hline Agf & Bansander & BMD & Credireal \\
\hline Agroinvest & Bansicredi & BMG & Credit Lyonnais \\
\hline Alfa & Barclays & BNB & Credit Suisse \\
\hline América do Sul & Basa & BNDES & Credito Sp \\
\hline Amex & BB & BNL & Crefisul \\
\hline Aplicap & BBA-Creditanstalt & BNP Paribas & Cruzeiro do Sul \\
\hline Araucaria & Bbc & Boavista & CSFB Garantia \\
\hline Arbi & BBM & Bonsucesso & Daimlerchrysler \\
\hline Argentaria & BBV Banco & Boreal & Daycoval \\
\hline Bamerindus & BCN & Bozano Simonsen & DBLABM \\
\hline Banap & BCO BFB & Bradesco & Destak \\
\hline Bancap & BCO John Deere & Brascan & Deutsch \\
\hline Bancional & Bco Planibanc & BRB & Deutsche \\
\hline
\end{tabular}

14 CONTEXTUS Revista Contemporânea de Economia e Gestão. Vol.5 - No 2 - jul/dez/2007. (07-20). 


\begin{tabular}{|c|c|c|c|}
\hline Bancnácion & Bcomuruguai & BRDE & Dibens \\
\hline Banco Bmc & BDMG & BRJ & Dresdner \\
\hline Bancoob & BEA & BVA & Emblema \\
\hline Bandeirantes & Beal & Cacique & Empresarial \\
\hline Bandepe & BEC & Cambial & Europeu \\
\hline Baneb & BEG & Cargill & Excel \\
\hline Baner & BEM & Cédula & Exteribank \\
\hline Banerj & Bemat & CEF & Fator \\
\hline Banese & BEMGE & Chase & Fibra \\
\hline Banespa & BEPI & Citibank & Ficrisa Axelrud \\
\hline Banestado & Besc & Clássico & Ficsa \\
\hline Banestes & BGN & Cnh Capital & FIDIS \\
\hline Banfort & $\mathrm{BIC}$ & Comercial Sp & Financial \\
\hline Bank Of America & Bilbao Vizcaya & Continental & Fininvest \\
\hline Bankboston & $\mathrm{Bm \& F}$ & Credibanco & Ford \\
\hline Frances Inter & Luso Brasileiro & Porto Seguro & Stock \\
\hline Ge Capital & Mappin & Português & Sudameris \\
\hline Geral do Comercio & Matone & Pottencial & Sul America \\
\hline Gerdau & Máxima & Premier & Sumitbank \\
\hline GM & Maxinvest & Primus & Theca \\
\hline Goldman Sachs & Mercantil do Brasil & Produban & Tokyo-Mitsubishi \\
\hline Guanabara & Mercantil Finasa & Prosper & Toyota \\
\hline Hispano & Mercantil Sp & PSA Finance & Triangulo \\
\hline Honda & Mercapaulo & Rabobank & Tricury \\
\hline HSBC & Meridional & Real & UBS Warburg \\
\hline Ibibank & Minas & Rede & Unibanco \\
\hline Induscred & Modal & Rendimento & Union \\
\hline Industrial do Brasil & Morada & Renner & Universal \\
\hline Indusval & Morgan Stanley & Ribeirao Preto & Uno - E \\
\hline ING & Nederlanden & Rural & Veja \\
\hline Inter Amex & Nossa Caixa & Safra & Volkswagen \\
\hline Intercap & Omega & Santander Banespa & Volvo \\
\hline Interior & Opportunity & Santander Brasil & Votorantim \\
\hline Interunion & Ourinvest & Santos & VR \\
\hline Investcred & Pactual & Santos Neves & Wachovia \\
\hline Itaú & Panamericano & Schahin & Westlb \\
\hline Jp Morgan Chase & Paraiban & Segmento & Zogbi \\
\hline KEB & Parana & SMBC & \\
\hline La Provincia & Patagon & Societe Generale & \\
\hline La Republica & PEBB & Socopa & \\
\hline Lage Landen & Pecunia & Sofisa & \\
\hline Lavra & Pine & Sogeral & \\
\hline Lemon Bank & Planibanc & SRL & \\
\hline Lloyds & Pontual & SS & \\
\hline Lógica & Porto Real & Sterling & \\
\hline
\end{tabular}

Quadro 3. Bancos analisados nesta pesquisa.

Fonte: Elaborado pelos autores 


\subsection{Hipótese e Construção das variáveis}

A Hipótese desenvolvida a partir do referencial teórico deste trabalho é:

$\mathrm{H}_{1}$ : Os bancos que participaram dos processos de $\mathrm{F} \& \mathrm{~A}$ no setor bancário brasileiro aumentaram os seus retornos.

Para testar as possíveis relações entre as variáveis implicadas na discussão foram desenvolvidas as proxies apresentadas abaixo.

\subsubsection{Variáveis Dependentes}

A primeira variável dependente do modelo será o ROE (1), Retorno sobre o Patrimônio Líquido. Este índice é calculado pela relação entre o lucro líquido e o patrimônio líquido (o total de recursos próprios investidos); tal indicador mede o retorno obtido sobre o investimento dos proprietários da empresa, e é uma função da rentabilidade das vendas (as margens líquidas) e do giro do patrimônio líquido (ASSAF NETO, 2002).

A segunda variável dependente do modelo foi o ROA (2), Retorno sobre o Ativo Total. Este índice constitui um dos mais importantes indicadores de rentabilidade da firma. Ele é calculado pela relação entre o lucro líquido e o ativo total. Esta taxa mede a eficiência global da administração da empresa na geração de lucros com seus ativos disponíveis (ASSAF NETO, 2002).

O uso dessas duas variáveis para medir o desempenho no setor é corroborado por Carvalho, Studart e Alves Jr (2002).

\subsubsection{Variáveis Independentes}

A primeira variável independente (1) do modelo foi o grau de alavancagem dos bancos (leverage). Esta variável é estimada através da relação entre o ativo total e o patrimônio líquido. Segundo Basu et al (2004), uma alta taxa de alavancagem indica um alto risco em caso de "corrida bancária".

A segunda variável independente (2) do modelo foi o nível de preços do PIB Real, colhida no site do IPEADATA, Instituto de Pesquisa Econômica Aplicada. Esta variável foi utilizada no modelo por se tratar de indicador chave no crescimento da economia.

A terceira variável independente (3) do modelo foi a taxa SELIC anual, taxa que baliza as negociações com títulos públicos no mercado monetário brasileiro e que é controlada pelo Sistema Especial de Liquidação e Custódia, um órgão do Banco Central do Brasil.

O SELIC (órgão) publica todos os dias as taxas de juros das negociações com títulos públicos realizadas no mercado monetário. Na visão de Assaf Neto (2003, p.73), a importância e a alta liquidez desta taxa repercutem intensamente em todo o mercado financeiro brasileiro sendo uma relevante referência para a formação das taxas de juros do mercado.

A quarta variável independente (4) do modelo foi a taxa anual do C-BOND (em pontos). Para Dezordi (2002), esta corresponde à taxa de juros que os certificados de dívida do governo brasileiro pagam acima do rendimento dos títulos do Tesouro Americano.

A quinta variável independente (5) foi uma variável binária (dummy); distinguirá os bancos que participaram dos processos de F\&A dos que não participaram. Esta variável segrega- rá a amostra em duas partes, sendo uma para aqueles que adquiriram outros bancos no período amostral e a outra para aqueles que não adquiriram nenhum banco no período amostral.

A justificativa para a escolha das variáveis independentes é motivada pelo fato de que os bancos instalados no Brasil possuem uma grande fonte de geração de rentabilidade através da intermediação de títulos da dívida pública brasileira. E há consenso sobre o fato de que estes índices afetam significativamente os valores de tais títulos.

Além do já mencionado, o uso de múltiplas variáveis contábeis e variáveis econômicas para o desempenho dos bancos, conforme descrito por Basu et al (2004), é significante para compensar a falta de determinada variável de mercado específica ao setor financeiro.

\subsection{Modelo econométrico}

Para análise da hipótese $\mathrm{H}_{1}$, utilizou-se um modelo de regressão com dados em painel, segundo proposta de Basu et al (2004), o qual investiga se os processos de F\&A estão correlacionados com os retornos dos bancos.

Basu et al (2004) testaram este modelo nos processos de F\&A na Argentina no período de 1995 a 2000. Os dados utilizados nesta pesquisa serão similares aos utilizados no modelo de Basu et al (2004), que inclui informações do setor público, privado, bancos com controle estrangeiro e com controle nacional.

Os retornos dos bancos são apresentados através do seguinte modelo:

$$
\mathrm{r}_{\mathrm{it}}=\alpha+\mathrm{x}_{\mathrm{it}} \beta D_{\mathrm{i}}+\varepsilon_{\mathrm{it}}
$$

Onde i denota a cross-sections and t denota time-series com $i=1,2, \ldots, n$, e t $=1,2, \ldots, t$; a variável dependente rit são os retornos dos bancos; $\alpha$ é uma escalar; $\beta$ é o vetor dos coeficientes; e xit é a it-nésima observações das variáveis explanatórias. O termo Di é a variável binária referente ao fator "participação em fusões e aquisições". O modelo (1) é similar ao utilizado por Basu et al (2004), com algumas mudanças necessárias às características do mercado brasileiro.

\section{RESULTADOS E DISCUSSÃO}

Os testes apresentados contemplam apenas o ROE. Foram feitos os mesmo testes com o ROA e os resultados não foram diferentes. Desta forma, decidiu-se apresentar apenas os valores referentes ao Retorno sobre o Patrimônio Líquido. A tabela 1 mostra a estatística descritiva dos resultados.

A tabela 1 descreve os resultados da regressão em que o ROE é a variável independente e as variáveis explanatórias são: a alavancagem (leverage), o PIB, o C-Bond e a Selic. A composição desta amostra foi de 232 bancos com informações de 1995 a 2004.

Pelos resultados expostos na tabela 1 , percebe-se que a média e a mediana do ROE e da Leverage não estão muito próximas, indicando que a distribuição não é simétrica e que há valores extremos afetando estas médias. Ao analisar os valores mínimos e máximos, pode-se notar também que existem valores muito distantes do padrão, quando comparados com as médias e com 
Tabela 1: Estatística descritiva dos resultados.

\begin{tabular}{lcccccc}
\hline & ROE & Leverage & IPCA & PIB & C-Bond & Selic \\
\hline Média & 0,0237 & 9,2468 & 0,0760 & 0,0220 & 0,0427 & 0,2422 \\
Mediana & 0,0643 & 6,7178 & 0,0767 & 0,0193 & 0,0411 & 0,2098 \\
Máximo & 2,3502 & 537,5478 & 0,1253 & 0,0494 & 0,9207 & 0,4204 \\
Mínimo & $-13,4644$ & $-14,3519$ & 0,0166 & 0,0013 & $-0,6655$ & 0,1536 \\
Desvio Padrão & 0,5870 & 21,2725 & 0,0297 & 0,0156 & 0,5044 & 0,0827 \\
Observações & 1060 & 1060 & 1060 & 1060 & 1060 & 1060 \\
\hline
\end{tabular}

Fonte: Elaborado pelos autores a partir da análise dos dados

as medianas da amostra. Pode-se observar, ainda, que o desvio padrão é bastante diferente em cada uma das variáveis analisadas, indicando que existe uma grande heterogeneidade da amostra.

Tabela 2. Resumo da Regressão utilizando ROE como Variável Dependente. nos processos de F\&A no mercado italiano; e com os encontrados por Basu et al (2004) no mercado argentino. Em ambos os estudos não houve evidências para se afirmar que os bancos adquirentes tiveram seus retornos aumentados após os processos de F\&As.

Tabela 2: Resumo da Regressão utilizando ROE como Variável Dependente.

\begin{tabular}{|c|c|c|c|c|}
\hline Variáveis & Coefic. & Erro Padrão & T-Stat & P-Value \\
\hline Leverage & $-0,0076$ & 0,0008 & $-9,2994$ & 0,0000 \\
\hline Pib & 1,3894 & 1,0465 & 1,3277 & 0,1846 \\
\hline C-Bond & $-0,0676$ & 0,0365 & $-1,8522$ & 0,0643 \\
\hline Selic & 0,2430 & 0,1169 & 2,0787 & 0,0379 \\
\hline Adqte & 0,0603 & 0,0532 & 1,1335 & 0,2573 \\
\hline $\mathrm{R}^{2}$ & 0,079864 & & & \\
\hline $\mathrm{R}^{2}$ Ajustado & 0,075499 & & & \\
\hline Durbin-Watson & 1,899888 & & & \\
\hline Cross-Section Included & 202 & & & \\
\hline Total de Observations (unbalanced) & 1.060 & & & \\
\hline
\end{tabular}

Fonte: Elaborado pelos autores a partir da análise dos dados

Conforme os resultados descritos na tabela 2 , detecta-se que a variável leverage possui o sinal do coeficiente negativo, porém com uma correlação que se aproxima de zero. Isto significa dizer que há uma relação negativa significante a 0,01 , com coeficiente de reação de 0,0076 entre alavancagem e ROE. A variável C-Bond tem coeficiente negativo, seguindo a discussão anterior, porém com significância a 0,10 com um coeficiente de relação de - 0,0676. Um aumento na variação do C-Bond reduz o ROE. Já a variável Selic tem relação positiva com o ROE, com um coeficiente de 0,2430 e uma significância de 0,0379.

De fato, espera-se que fatores macroeconômicos afetem com mais intensidade os resultados do setor bancário - o que foi corroborado pelos resultados acima. Dessa forma, na amostra estudada não há evidências para afirmar que os bancos que participaram dos processos de F\&A apresentam um comportamento diferenciado nos seus retornos.

Estes resultados são consistentes com os obtidos por Focareli, Panetta e Salleo (2003), que não encontraram evidências

\section{CONSIDERAÇÕES FINAIS}

Neste trabalho demonstrou-se que o processo de F\&A no setor financeiro não estaria associado ao aumento dos retornos medidos através do ROE e ROA, rejeitando-se a hipótese da maximização dos lucros da firma. Uma possível explicação para estes resultados diferentes do que preconiza a teoria econômica pode residir no período estudado.

Além disso, para Patrocínio, Kayo e Kimura (2005), a nova onda de F\&A é motivada muito mais por questões estratégicas e de criação de barreira de entrada a novos concorrentes do que por ganhos financeiros rápidos.

Corroborando esta idéia, Paula (2004) afirma que os bancos brasileiros reagiram fortemente à entrada dos bancos europeus no Brasil na década de 90. A partir de 1995, bancos como o Bilbao Vizcaya, Santander, ABN-Amro e HSBC atuaram fortemente no mercado brasileiro, comprando o Excel/ econômico, o Banco Noroeste, o Real e o Bamerindus. Entre- 
tanto, segundo o autor, os resultados empíricos falharam em demonstrar que os bancos estrangeiros são mais eficientes que os nacionais, e que a entrada destes bancos no Brasil contribuiu para uma reorientação estratégica da atividade financeira.

Dentre as diversas formas e fatores que podem ser determinantes no estudo da performance financeira, esta pesquisa restringe-se à avaliação dos impactos das F\&As nos retornos dos bancos adquirentes. Diante das evidências, novas pesquisas poderiam ser desenvolvidas no intuito de identificar quais seriam as reais motivações deste processo de combinação de instituições financeiras na era pós-Plano Real.

Dentre os possíveis caminhos a serem trilhados, sugerese a análise da vinculação das referidas operações e a criação de barreiras de entrada. Desse modo, as instituições financeiras não necessariamente estariam aumentando seu retorno, mas sim diminuindo os riscos de novos entrantes no mercado. Uma outra possibilidade seria a avaliação do ROA e do ROE em períodos subseqüentes, identificando a obtenção de melhores rentabilidades como uma estratégia de longo prazo.

\section{REFERÊNCIAS}

ASSAF NETO, Alexandre. Estrutura e Análise de Balanços. 7. ed. São Paulo: Atlas, 2002.

Finanças Corporativa e Valor. São Paulo: Atlas, 2003.

BANCO CENTRAL DO BRASIL - BACEN. Site da organização. Disponível em <http://www.bacen.gov.br>. Acesso em 29 de Novembro de 2005

BASU, Ritu et al. Bank Consolidation and Performance: the argentine experience, IMF working papers 04/149. International Monetary Fund, 2004.

BRIGHAM, Eugene F.; GAPENSKI, Louis C.; EHRHARDT, Michael C. Administração Financeira: Teoria e Prática. São Paulo: Atlas, 2001.

BRITO, Giovani A. Silva; BATISTELA, Flávio Donizete; FAMÁ, Rubens. Fusões e aquisições no setor bancário: avaliação empírica do efeito sobre o valor das ações. Revista de Administracão. São Paulo: FEA/USP, v.40, n.4, p.353-360, out/nov/dez 2005.

CAMARGOS, Marcos Antônio de; BARBOSA, Francisco Vidal. Fusões, aquisições e takeovers: um levantamento teórico dos motivos, hipóteses testáveis e evidências empíricas. Caderno de Pesquisa em Administração. São Paulo: PPGA/FEA/USP, v.10, n.2, p.17-38, abr/jun 2003.

Análise empírica da hipótese de maximização da riqueza dos acionistas nos processos de fusão e aquisição ocorridos no mercado de capitais brasileiros pós Plano Real. In: ENCUENTRO INTERNACIONAL DE FINANZAS, 28, 2004, Viña del Mar. Anais... 2004.

. Análise empírica do retorno acionário anormal e da reação do mercado de capitais brasileiro aos anúncios de fusões e aquisições entre 1994 e 2001. In: ENCONTRO NACIONAL DE PÓSGRADUAÇÃO EM ADMINISTRAÇÃO, 28, 2005, Brasília/DF. Anais... 2005. 1 CD-ROM.

DEZORDI, L. L. Risco-Brasil: Mitos e Verdades. Disponível em: $<$ www.fae.edu>. Acessado em: 23 de Abril de 2005.

DODD, Peter. Merger proposal, management discretion and stockholder weath. Journal of Financial Economics. Amsterdam: North Holland. v.8, n.2, p.105-137, jun 1980.
FIRTH, Michael. Synergism in mergers: some British results. The Journal of Finance. Chicago: American Finance Association. v.33, n.2, p.670-672, may 1978.

FOCARELLI, Dario; PANNETA, Fabio; SALLEO, Carmelo. Why do banks merger? CEIS Tor Vergata - Research Paper Series, v.2003, n.03, jan 2003.

GIL, Antonio Carlos. Como elaborar projetos de pesquisa. 4. ed. São Paulo: Atlas, 2002.

GITMAN, Lawrence J. Princípios de Administração Financeira. 7. ed. São Paulo: Habra, 2002.

GONÇALVES, Odair; OTT, Ernani. A Evidenciação nas Companhias Brasileiras de Capital Aberto. In: ENCONTRO NACIONAL DE PÓSGRADUAÇÃO EM ADMINISTRAÇÃO, 26, 2002, Salvador, BA Anais... 2002. 1 CD-ROM.

GOSH, Aloke. Does operating performance really improve following corporate acquisitions? Journal of Corporate Finance. Amsterdam: Elsevier Science. v.7, n.2, p.151-178, jun 2001.

JENSEN, Michael C. Agency costs of free cash flow, corporate finance, and takeovers. American Economic Review. Nashville: American Economic Association. vol.76, n.2, p.323-329, May 1986.

KLOECKNER, Gilberto de Oliveira. Fusões e aquisições: motivos e evidência empírica. Revista de Administração. São Paulo: FEA/ USP, V.29, n.1, p.42-58, Jan./Mar. 1994.

KUPFER, David; HASENCLEVER, Lia (org.) Economia industrial: fundamentos teóricos e práticos no Brasil. Rio de Janeiro: Campus, 2002.

MANNE, Henry G. Mergers and the market for corporate control. The Journal of Political Economy. Chicago: The University of Chicago Press. v.73, n.4, p.110-120, Apr 1965.

MARTINS, Gilberto de Andrade; LINTZ, Alexandre. Guia para elaboração de monografia e trabalbos de conclusão de curso. São Paulo: Atlas, 2001.

NAKANE, Márcio I.; ALENCAR, Leonardo S. Análise de Fusões e Aquisições Horizontais no Setor Bancário: uma Reflexão a Partir da Experiência Internacional. Seminário de Economia Bancária e Crédito. São Paulo: Banco Central do Brasil. dez de 2004.

PATROCINIO, Maurício Réa; KAYO, Eduardo Kazuo; KIMURA, Hebert. Intangibilidade e criação de valor nos eventos de fusão e aquisição: uma análise dos retornos anormais no período de 1994 a 2004 In: ENCONTRO NACIONAL DE PÓS-GRADUAÇÃO EM ADMINISTRAÇÃO, 29, 2005, Brasília/DF. Anais... 2005. 1 CD-ROM.

PAULA, Luiz Fernando de. Determinantes e impactos da recente entrada de bancos europeus no Brasil. Economia. Curitiba: UFPR. v.30, n.2, p.35-77, jul/dez 2004.

RAPPAPORT, Alfred. Creating shareholder value: a guide for managers and investors. 2nd Edition, New York: The Free Press, 1998.

ROSS, Stephen A.; WESTERFIELD, Randolph W.; JAFE, Jeffrey F. Administração Financeira: Corporate Finance. 2. ed. São Paulo: Atlas, 2002

SHLEIFER, Andrei; VISHNY, Robert W. Value maximization and the acquisition process. Journal of Economic Perspectives. Nashville: American Economic Association. v.2, n.1, p.7-20, Winter 1988.

SICHERMAN, Neil W.; PETTWAY, Richard H. Acquisition of Divested Assets and Shareholders' Wealth. The Journal of Finance. Chicago: American Finance Association. v.42, n.5, p.1261-1273, dec. 1987.

STEVENSON, W.J. Estatística Aplicada à Administração. São Paulo: Harbra, 1986.

SZÜSTER, Natan; SZÜSTER, Fortunée Rechtman; SZÜSTER, Flávia Rechtman. Contabilidade: Atuais desafios e alternativa para 
seu melhor desempenho. Revista Contabilidade \& Finanças. São Paulo: FEA/USP, n. 38, p.20-30, mai/ago 2005.

TRICHES, Divanildo. Fusões, aquisições e outras formas de associação entre empresas no Brasil. Revista de Administração. São Paulo: FEA/USP, v.31, n.1, p.14-31, jan./mar. 1996. 
